\title{
Corrigendum
}

\section{Comprehensive biometric, biochemical and histopathological assessment of nutrient deficiencies in gilthead sea bream fed semi-purified diets - CORRIGENDUM}

Gabriel F. Ballester-Lozano, Laura Benedito-Palos, Itziar Estensoro, Ariadna Sitjà-Bobadilla, Sadasivam Kaushik and Jaume Pérez-Sánchez

(First published online: 29 July 2016)

doi: 10.1017/S0007114515002354, Published by Cambridge University Press, 29 July 2015.

\section{Original text and correction}

Original: In page 718 , Table 4 , in the third row entry, first column the original text reads: RBC $\times 10^{-6} / \mathrm{ml}$ Correction: RBC x $10^{6} / \mu \mathrm{l}$ 